\title{
Role of Pelvic Lymph Node Resection in Vulvar Squamous Cell Cancer: A Subset Analysis of the AGO-CaRE-1 Study
}

\begin{abstract}
Linn Woelber, MD ${ }^{1}$, Mareike Bommert, $\mathrm{MD}^{2}$, Philipp Harter, $\mathrm{MD}^{2}$, Katharina Prieske, $\mathrm{MD}^{1,3}$, Christine zu Eulenburg, $\mathrm{PhD}^{4}$, Julia Jueckstock, $\mathrm{MD}^{5}$, Felix Hilpert, $\mathrm{MD}^{6}$, Nikolaus de Gregorio, $\mathrm{MD}^{7}$, Severine Iborra, $\mathrm{MD}^{8}$, Jalid Sehouli, $\mathrm{MD}^{9}$, Atanas Ignatov, $\mathrm{MD}^{10}$, Peter Hillemanns, $\mathrm{MD}^{11}$, Sophie Fuerst, $\mathrm{MD}^{5}$, Hans-Georg Strauss, $\mathrm{MD}^{12}$, Klaus Baumann, $\mathrm{MD}^{13}$, Matthias Beckmann, $\mathrm{MD}^{14}$, Alexander Mustea, $\mathrm{MD}^{15}$, Werner Meier, $\mathrm{MD}^{16}$, Sven Mahner, $\mathrm{MD}^{5}$, and Anna Jaeger, $\mathrm{MD}^{1}$

${ }^{1}$ Department of Gynecology and Gynecologic Oncology, University Medical Center Hamburg-Eppendorf, Hamburg, Germany; ${ }^{2}$ Department of Gynecology and Gynecologic Oncology, Evang. Kliniken Essen-Mitte, Essen, Germany; ${ }^{3}$ Mildred Scheel Cancer Career Center HaTriCS4, University Medical Center Hamburg-Eppendorf, Hamburg, Germany; ${ }^{4}$ Department of Epidemiology, UMCG, Universität Groningen, Groningen, The Netherlands; ${ }^{5}$ Department of Obstetrics and Gynecology, University Hospital, LMU - University of Munich, Munich, Germany; ${ }^{6}$ Oncologic Medical Center at the Jerusalem Hospital Hamburg, Hamburg, Germany; ${ }^{7}$ Department of Obstetrics and Gynecology, University of Ulm Medical Center, Ulm, Germany; ${ }^{8}$ Department of Gynecology and Gynecologic Oncology, University Hospital Aachen, RWTH Aachen, Aachen, Germany; ${ }^{9}$ Department of Gynecology, Charité University Medicine Berlin, Campus Virchow, Berlin, Germany; ${ }^{10}$ Department of Obstetrics and Gynecology, University Hospital Magdeburg, Magdeburg, Germany;

${ }^{11}$ Department of Obstetrics and Gynecology, Hannover Medical School, Hannover, Germany; ${ }^{12}$ Department of Gynecology, University Hospital Halle, Halle, Germany; ${ }^{13}$ Department of Gynecology, Medical Center Ludwigshafen, Ludwigshafen, Germany; ${ }^{14}$ Department of Gynecology and Obstetrics, University Hospital Erlangen, Comprehensive Cancer Center Erlangen-EMN, Friedrich-Alexander University Erlangen-Nuremberg, Erlangen, Germany; ${ }^{15}$ Department of Gynecology and Gynecologic Oncology, University Medical Center Bonn, Bonn, Germany; ${ }^{16}$ Department of Obstetrics and Gynecology, Evangelical Hospital Duesseldorf, Duesseldorf, Germany
\end{abstract}

\section{ABSTRACT}

Background. As the population at risk for pelvic nodal involvement remains poorly described, the role of pelvic lymphadenectomy (LAE) in vulvar squamous cell cancer (VSCC) has been a matter of discussion for decades.

Methods. In the AGO-CaRE-1 study, 1618 patients with International Federation of Gynecology and Obstetrics (FIGO) stage IB or higher primary VSCC treated at 29

Linn Woelber and Mareike Bommert have contributed equally to this work.

(C) The Author(s) 2021

First Received: 6 November 2020

Accepted: 4 February 2021;

Published Online: 15 March 2021

L. Woelber, MD

e-mail: 1woelber@uke.de centers in Germany between 1998 and 2008 were documented. In this analysis, only patients with pelvic LAE $(n=70)$ were analyzed with regard to prognosis and correlation between inguinal and pelvic lymph node involvement.

Results. The majority of patients had T1b/T2 tumors $(n=47 ; 67.1 \%)$, with a median diameter of $40 \mathrm{~mm}$ (2-240 mm); 54/70 patients $(77.1 \%)$ who received pelvic LAE had positive groin nodes. For 42 of these 54 patients, the number of affected groin nodes had been documented as a median of $3 ; 14 / 42(33.3 \%)$ of these patients had histologically confirmed pelvic nodal metastases (median number of affected pelvic nodes 3 [1-12]). In these 14 patients, the median number of affected groin nodes was 7 (1-30), with a groin metastases median maximum diameter of $42.5 \mathrm{~mm}$ (12-50). Receiver operating characteristic analysis showed an area under the curve of 0.85 , with $83.3 \%$ sensitivity and $92.6 \%$ specificity for the prediction of pelvic involvement in cases of six or more positive groin 
nodes. No cases of pelvic nodal involvement without groin metastases were observed. Prognosis in cases of pelvic metastasis was poor, with a median progression-free survival of only 12.5 months.

Conclusion. For the majority of node-positive patients with VSCC, pelvic nodal staging appears unnecessary since a relevant risk for pelvic nodal involvement only seems to be present in highly node-positive disease.

Pelvic nodal involvement in primary vulvar squamous cell cancer (VSCC) is considered rare, and it is estimated that $<10 \%$ of all VSCCs and $<2 \%$ of early VSCCs show nodal spread beyond the groin to the pelvis. ${ }^{1-4}$ The question of when and if pelvic lymphadenectomy (LAE) should be performed in VSCC has been the subject of discussion since the 1980s. The Gynecologic Oncology Group (GOG) addressed the question in a randomized trial (GOG37) by Homesley et al. ${ }^{5}$ Patients with histologically confirmed inguinal lymph node metastases after surgical groin dissection received either 45-50 Gy of radiotherapy to both the groin and the pelvis, or pelvic LAE without any adjuvant radiotherapy. In $15 / 53$ patients $(28.3 \%)$ in the pelvic LAE group, histologically confirmed positive pelvic nodes were detected. The GOG37 study was closed earlier than planned due to a significant survival benefit in the radiotherapy group. Since the publication of these study results, adjuvant radiotherapy of the groin and pelvis has been implemented as the standard therapeutic approach to VSCC with more than one lymph node metastasis in the groin; however, due to the design of the study, interpretation of the results remains difficult. Two-year overall survival (OS) was superior in the radiotherapy group compared with the pelvic LAE group' (68\% vs. 54\%), while the pelvic recurrence rate was higher in the 'radiotherapy group' (6\% vs. $2 \%)$. The poor outcome of the pelvic LAE group can mainly be attributed to the omission of adjuvant radiotherapy to the groin in this group, resulting in a higher groin recurrence rate of $23.6 \%$, compared with only $5.1 \%$ in the radiotherapy group, as the prognosis of groin recurrences is known to be fatal in the majority of cases, with a 5 -year OS rate of only $20 \%{ }^{6}$ The named study could therefore not clarify the role of pelvic LAE in node-positive VSCC.

As the overall risk for pelvic nodal involvement is estimated to be $20-35 \%$ in node-positive VSCC and radiotherapy of the pelvis can cause substantial morbidity, especially in the elderly population affected by VSCC, it is currently recommended by some treatment guidelines to perform systematic pelvic LAE as a staging procedure (by the minimally invasive or retroperitoneal approaches) in patients at risk for pelvic nodal involvement; ${ }^{7}$ however, this approach often requires secondary surgery with increased morbidity and the population at risk is poorly defined. In a pilot study from Charité Berlin, 12 patients with node-positive primary or recurrent VSCC (1-7 affected groin nodes) received pelvic LAE, however only two of these patients showed pelvic nodal involvement $(17 \%)^{3}$. The risk of pelvic nodal metastases appears to increase with the number of affected groin nodes. ${ }^{8,9}$ According to the German guideline, patients at risk for pelvic metastases include patients with one groin metastasis $>5 \mathrm{~mm}$, patients with two or more groin metastases (including bilateral involvement), and metastases with extracapsular spread. ${ }^{7}$ These characteristics are known to be associated with poor prognosis in general. The role of pelvic nodal involvement in this subgroup and its impact on prognosis is still unclear. Furthermore, the questions as to when and how to perform pelvic LAE, as well as the optimal extent of pelvic treatment generally in patients with node-positive VSCC, is still surrounded by considerable controversy. Therefore, the aim of the current study was to analyze the relation between lymph node involvement of the groin and pelvis and the relevance of pelvic metastasis for prognosis based on all patients who were treated with pelvic LAE within the Arbeitsgemeinschaft Gynäkologische Onkologie-Chemo and Radiotherapy in Epithelial Vulvar Cancer-1 (AGO-CaRE-1) study.

\section{METHODS}

The current analysis evaluated a subgroup of the AGOCaRE-1 study. ${ }^{10}$ The aim of the AGO-CaRE-1 study, a large retrospective study, was to survey treatment patterns as well as prognostic factors in VSCC. Overall, 1618 patients with International Federation of Gynecology and Obstetrics (FIGO) stage IB or higher primary VSCC (Union for International Cancer control [UICC] TNM classification and stage groupings version 6) treated at 29 gynecologic cancer centers in Germany between 1998 and 2008 were included..$^{11}$ Participating institutions were asked to include all patients with a diagnosis of stage $>$ pT1a invasive vulvar cancer, independent of the mode and initial place of treatment. Data collection was performed retrospectively between February and December 2011. Documentation and analysis were undertaken by the AGO study group through a specifically designed centralized database. The study was approved by each local Ethics Committee (leading vote: Hamburg, reference number PV3658, and registered with ClinialTrials.gov [NCT01304667]). The results of the main analysis have been previously published. ${ }^{10}$ This subset analysis is a retrospective data collection study that focuses on patients with pelvic LAE $(n=70)$, and evaluates, in particular, the occurrence of pelvic nodal involvement at primary 
diagnosis as well as the correlation between inguinal and pelvic nodal involvement. Furthermore, the impact of pelvic nodal metastases on prognosis was investigated.

\section{Statistical Analysis}

Analysis was performed using Stata version 14.2 (StataCorp LLC, College Station, TX, USA). Variables are described as median and range or count and percentage. Receiver operating characteristics (ROC) analysis was performed and the area under the curve (AUC) was calculated to evaluate different cut-offs for the prediction of pelvic nodal involvement related to the number of affected groin nodes. Progression-free survival (PFS) was calculated as the time interval between primary diagnosis and disease progression or death of any cause, while OS was defined as the period from primary diagnosis to death of any cause. Univariate Cox regression analysis was applied to determine significant differences at a level of 5\%.

\section{RESULTS}

\section{Patients}

Of 1618 patients with stage IB-IV VSCC treated between 1998 and 2008 at one of the 29 participating German cancer centers, only 70 patients received surgical staging of the pelvis (pelvic LAE) and had a known lymph node status of the groin ( $n=54$ node-positive; $n=16$ node-negative). Patient characteristics are displayed in Table 1. Median age was 63 years (range 20-85) and median follow-up was 31 months (range 1-140). The majority of patients had locally restricted tumors (T1b/T2; TNM staging system version 6: 47/70, 67.1\%), which were predominantly resected with tumor-free margins (41/57 R0, $71 \%){ }^{12}$

Overall, 54/70 patients with pelvic LAE (77.1\%) showed positive inguinal nodes $(\mathrm{N}+)$. In the total cohort, pelvic nodal involvement without groin metastases was not observed. Information regarding the number of groin nodes affected was available in 42 node-positive patients (median number of nodes affected $=3$ ); 14/42 (33\%) patients showed both inguinal and pelvic metastases, with a median of 3 (range 1-12) affected pelvic lymph nodes. In the pelvic node-positive group, the median number of affected groin nodes was 7 (range 1-30), with a median metastatic diameter of $42.5 \mathrm{~mm}$ (range 12-50). Ten pelvic nodepositive patients had six or more positive lymph nodes in the groin, while one patient had just one groin node metastasis (Table 2); unfortunately, the size of the groin metastasis was not available in this particular patient. ROC analysis showed an AUC of 0.85 , with $83.3 \%$ sensitivity and $92.6 \%$ specificity for the prediction of pelvic involvement in cases of six or more positive groin nodes (Fig. 1).

A total of $42.9 \%(30 / 70)$ of patients experienced any kind of disease recurrence after a median of 9.2 months (range 1.5-73.1) [Table 3]. However, while taking into account the fact that the radiotherapy fields were not documented in all patients (see Table 1), 50\% (7/14) and 28\% (12/43) of the pelvic node-positive and pelvic node-negative patients, respectively, received radiotherapy including the pelvis. No pelvic recurrences were observed in the pelvic node positive group whereas pelvic recurrences occured in 7\% (3/43 patients) within the pelvic node negative group. In the pelvic node-positive group, $28.6 \%$ (4/ 14) of patients experienced distant recurrences as the most frequent site, followed by local recurrences on the vulva in $21.4 \%(3 / 14)$ of patients. In the pelvic node-negative group, recurrences appeared most often on the vulva (10/43 patients, 23.3\%), followed by the pelvis and distant metastases in 3/43 (7\%) patients. Death before recurrence occurred in $11.4 \%(8 / 70)$ of patients after 21.1 months (range 1.31-45.83). As expected, the risk of recurrence was higher in the pelvic node-positive group compared with the pelvic node-negative group (8/14 patients [57.1\%] vs. $17 / 43$ patients [39.5\%]). Within the 31-month follow-up, $51.2 \%$ (22/43) of node-negative patients versus $28.6 \%$ (4/ 14 ) of node-positive patients remained free of recurrences.

The median PFS for all patients, regardless of pelvic node status, was 35.2 months, while the median OS was not reached. In the case of pelvic metastasis, prognosis was significantly impaired, with a median PFS of only 12.5 months and a median OS of 30.8 months (Fig. 2).

\section{Discussion}

When and how to treat the pelvis in patients with nodepositive VSCC is still an open question. Pelvic LAE as a staging procedure in patients with inguinal node-positive VSCC is subject to controversial discussion in many countries due to simultaneously performed irradiation of the groin and pelvis in the detection of groin metastases. This practice was implemented after publication of the GOG37 study in the 1980s, however this study was not designed to answer the question, "who actually benefits from pelvic treatment at all (radiotherapy and/or LAE)? The results of the current study confirm that pelvic nodal involvement can be expected in approximately $30 \%$ of all patients with positive groin nodes, which is in line with previously reported rates, namely the $28 \%$ described by Homesley et al. ${ }^{5}$ (15/53 patients). However, negative selection bias in the current analysis is likely, as the indication for pelvic LAE was individually posed, and a relative overestimation of pelvic involvement with regard 
TABLE 1 Patient characteristics $(n=70)$ with regard to pelvic lymph node status

\begin{tabular}{|c|c|c|c|c|c|}
\hline & $\begin{array}{l}\text { Total }[N= \\
70]\end{array}$ & $\begin{array}{l}\text { Pelvic status missing } \\
{[n=13]}\end{array}$ & $\begin{array}{l}\text { Pelvic } \mathrm{pN}+ \\
{[n=14]}\end{array}$ & $\begin{array}{l}\text { Pelvic } \mathrm{pN}- \\
{[n=43]}\end{array}$ & $\begin{array}{l}p \text {-value }(\mathrm{N}+ \\
\text { vs. } \mathrm{N}-)\end{array}$ \\
\hline Age, years [median (range)] & 63.0 & $(20.3-85.2)$ & $\begin{array}{l}68.1 \\
\quad(52.0-79.2)\end{array}$ & $\begin{array}{l}71.5 \\
\quad(31.5-82.8)\end{array}$ & $\begin{array}{l}56.2 \\
\quad(20.3-85.2)\end{array}$ \\
\hline \multicolumn{6}{|l|}{$0.026^{\mathrm{a}}$} \\
\hline \multicolumn{6}{|l|}{ Tumor stage } \\
\hline pT1b & 12 & 4 & 3 & 5 & $0.604^{\mathrm{b}}$ \\
\hline pT2 & 35 & 4 & 6 & 25 & \\
\hline pT3/4 & 1 & 0 & 0 & 1 & \\
\hline Unknown & 22 & 5 & 5 & 12 & \\
\hline \multicolumn{6}{|l|}{ Nodal status } \\
\hline pNO & 16 & 2 & 0 & 14 & $0.010^{\mathrm{b}}$ \\
\hline $\mathrm{pN} 1$ & 54 & 11 & 14 & 29 & \\
\hline $\begin{array}{l}\text { No. of groin nodes affected [median (range)], } \\
\quad n=42\end{array}$ & $3(1-30)$ & $2(2-2)$ & $7(1-30)$ & $2(1-10)$ & $0.001^{\mathrm{a}}$ \\
\hline $\begin{array}{l}\text { Maximum diameter of LN metastases of the groin, } \\
\text { mm (range), } n=9\end{array}$ & $27.0(1-50)$ & $10(10-10)$ & $42.5(12-50)$ & $23.5(1-32)$ & $0.187^{\mathrm{a}}$ \\
\hline $\begin{array}{l}\text { No. of pelvic nodes affected [median (range)], } \\
\quad n=14\end{array}$ & $2.5(1-12)$ & NA & $2.5(1-12)$ & NA & NA \\
\hline Tumor diameter, mm [median (range)], $n=53$ & $40(2-240)$ & $40(18-70)$ & $40(15-240)$ & $39(2-110)$ & $0.106^{\mathrm{a}}$ \\
\hline Depth of invasion, mm [median (range)], $n=26$ & $5.7(1.5-70)$ & $3(3-3)$ & $5.3(5-6)$ & $9(1.5-70)$ & $0.357^{\mathrm{a}}$ \\
\hline \multicolumn{6}{|l|}{ Grading } \\
\hline G1 & 3 & 0 & 0 & 3 & $0.024^{\mathrm{b}}$ \\
\hline G2 & 34 & 3 & 4 & 27 & \\
\hline G3 & 29 & 7 & 10 & 12 & \\
\hline Unknown & 4 & 3 & 0 & 1 & \\
\hline \multicolumn{6}{|l|}{ ECOG } \\
\hline 0 & 23 & 1 & 0 & 22 & $<0.001^{\mathrm{b}}$ \\
\hline 1 & 9 & 0 & 4 & 5 & \\
\hline 2 & 12 & 5 & 1 & 6 & \\
\hline 3 & 3 & 0 & 3 & 0 & \\
\hline 4 & 1 & 0 & 1 & 0 & \\
\hline Unknown & 22 & 7 & 5 & 10 & \\
\hline Surgical therapy vulva & & & & & $0.950^{\mathrm{b}}$ \\
\hline Partial vulvectomy & 19 & 2 & 3 & 14 & \\
\hline Complete vulvectomy & 45 & 10 & 10 & 25 & \\
\hline Exenteration/unknown & 6 & 1 & 1 & 4 & \\
\hline Resection margin, mm [median (range)], $n=19$ & $4(0.2-11)$ & $4.75(0.5-9)$ & $3(2-4)$ & $4(0.2-11)$ & $0.496^{\mathrm{a}}$ \\
\hline \multicolumn{6}{|l|}{ Resection status } \\
\hline R0 & 41 & & 9 & 32 & $0.443^{\mathrm{b}}$ \\
\hline $\mathrm{R} 1$ & 12 & & 3 & 9 & \\
\hline $\mathrm{Rx}$ & 4 & & 2 & 2 & \\
\hline \multicolumn{6}{|l|}{ Type of groin surgery } \\
\hline Complete (groin dissection) & 69 & 13 & 14 & 42 & $1.000^{\mathrm{b}}$ \\
\hline Sentinel (only) & 1 & 0 & 0 & 1 & \\
\hline \multicolumn{6}{|l|}{ Sentinel node biopsy performed } \\
\hline No & 47 & 5 & 12 & 30 & $0.024^{\mathrm{b}}$ \\
\hline Yes & 15 & 3 & 0 & 12 & \\
\hline Unknown & 8 & 5 & 2 & 1 & \\
\hline $\begin{array}{l}\text { No. of dissected LNs (groin) per patient } \\
\quad[\text { median (range)], } n=57\end{array}$ & $17(2-53)$ & $17(5-37)$ & $15(6-36)$ & $17(2-53)$ & $0.935^{\mathrm{a}}$ \\
\hline
\end{tabular}


TABLE 1 (continued)

\begin{tabular}{|c|c|c|c|c|c|}
\hline & $\begin{array}{l}\text { Total }[N= \\
70]\end{array}$ & $\begin{array}{l}\text { Pelvic status missing } \\
{[n=13]}\end{array}$ & $\begin{array}{l}\text { Pelvic } \mathrm{pN}+ \\
{[n=14]}\end{array}$ & $\begin{array}{l}\text { Pelvic } \mathrm{pN}- \\
{[n=43]}\end{array}$ & $\begin{array}{l}p \text {-value }(\mathrm{N}+ \\
\text { vs. } \mathrm{N}-\text { ) }\end{array}$ \\
\hline $\begin{array}{l}\text { No. of dissected LNs (pelvis) per patient } \\
\quad[\text { median (range)], } n=51\end{array}$ & $12(1-55)$ & NA & $10(1-28)$ & $13(2-55)$ & $0.761^{\mathrm{a}}$ \\
\hline \multicolumn{6}{|l|}{ Radiotherapy performed } \\
\hline Yes & 38 & 9 & 10 & 19 & \multirow[t]{3}{*}{0.171} \\
\hline No & 24 & 2 & 2 & 20 & \\
\hline Unknown & 8 & 2 & 2 & 4 & \\
\hline \multicolumn{6}{|l|}{ Type of radiotherapy } \\
\hline Adjuvant therapy & 33 & 8 & 8 & 17 & \multirow[t]{4}{*}{$0.213^{\mathrm{b}}$} \\
\hline Neoadjuvant therapy & 2 & 0 & 0 & 2 & \\
\hline Palliative & 3 & 1 & 2 & 0 & \\
\hline Unknown & 32 & 4 & 4 & 24 & \\
\hline \multicolumn{5}{|l|}{ Radiation fields } & \multirow[t]{6}{*}{$1.000^{\mathrm{b}}$} \\
\hline Groin \pm vulva & 8 & 1 & 2 & 5 & \\
\hline Groin and pelvis \pm vulva & 21 & 5 & 6 & 10 & \\
\hline Pelvis \pm vulva & 5 & 2 & 1 & 2 & \\
\hline Neither groin nor pelvis & 2 & 0 & 0 & 2 & \\
\hline Unknown & 34 & 5 & 5 & 24 & \\
\hline Median PFS (months) & 35.2 & 38.0 & 12.5 & 41.3 & $0.020^{\mathrm{c}}$ \\
\hline Median OS (months) & NR & 72.5 & 30.8 & NR & $0.003^{\mathrm{c}}$ \\
\hline
\end{tabular}

ANOVA analysis of variance, $L N$ lymph node, ECOG Eastern Cooperative Oncology Group, $P F S$ progression-free survival, $O S$ overall survival, $N R$ not reached, $n$. $a$. not applicable

${ }^{\mathrm{a}}$ ANOVA

${ }^{\mathrm{b}}$ Fisher's exact test

${ }^{\mathrm{c}}$ Cox regression analysis

'Missing' and 'unknown' categories excluded

TABLE 2 Relation between inguinal and pelvic nodal involvement ( $n=70$ patients with pelvic lymphadenectomy; $n=12$ pelvic nodepositive patients with known number of affected groin nodes)

\begin{tabular}{llll}
\hline $\begin{array}{l}\text { No. of positive } \\
\text { lymph nodes } \\
\text { (groin) }\end{array}$ & $\begin{array}{l}\text { No. of patients with } \\
\text { negative pelvic LN } \\
\text { status }\end{array}$ & $\begin{array}{l}\text { No. of patients with } \\
\text { positive pelvic LN } \\
\text { status }\end{array}$ & Total \\
\hline 1 & 7 & 1 & 8 \\
2 & 7 & 0 & 7 \\
3 & 7 & 1 & 8 \\
4 & 1 & 0 & 1 \\
5 & 3 & 0 & 3 \\
6 & 0 & 4 & 4 \\
8 & 0 & 2 & 2 \\
9 & 0 & 1 & 1 \\
10 & 2 & 0 & 2 \\
11 & 0 & 1 & 1 \\
12 & 0 & 1 & 1 \\
30 & 0 & 1 & 39 \\
Total & 27 & 12 & 1 \\
\hline
\end{tabular}

to all node-positive patients cannot be excluded. Nevertheless, this also means that approximately $70 \%$ of all node-positive patients likely do not need any kind of pelvic treatment or any surgical staging.

The main limitations of our data were that the data were generated in a period when preoperative radiologic staging was not routinely implemented as standard in all patients with locally advanced vulvar cancer, and that this was a post hoc analysis. Therefore, we missed the collection of data and/or scans of radiologic imaging. We know the limitation of imaging regarding inguinal nodes, but this is completely unknown for the question we addressed in this work.

Overall, the relatively low incidence of positive pelvic nodes, the increased surgical morbidity with potentially delayed adjuvant radiotherapy, and the generally poor prognosis of node-positive patients make it questionable as to whether there is sufficient justification for pelvic LAE as a staging procedure. Nonetheless, a subset of patients at high risk for pelvic nodal involvement may benefit from systematic pelvic LAE, when adjuvant radiotherapy to the pelvis can be avoided in the case of negative pelvic nodes. 


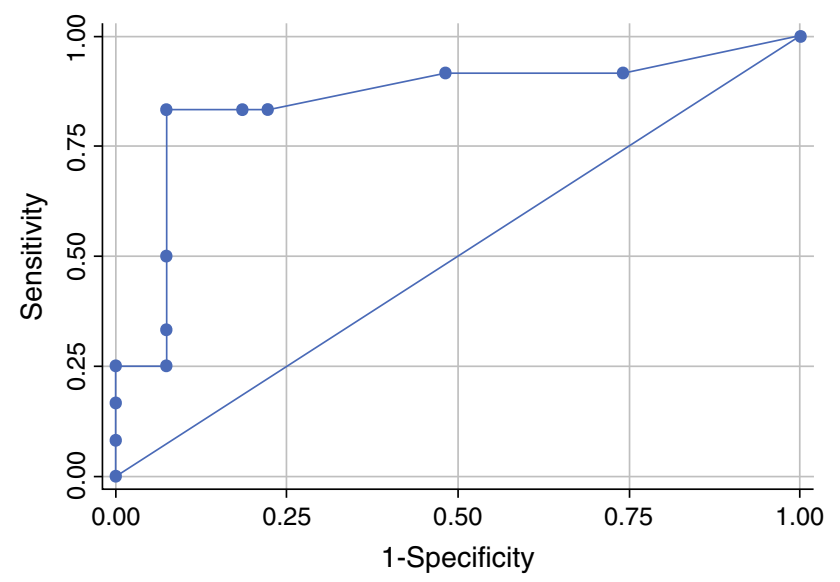

Area under ROC curve $=0.8549$

FIG. 1 Prediction of pelvic involvement depending on the number of inguinally affected lymph nodes. ROC receiver operating characteristic

This could be especially relevant for younger women with open family planning or patients with comorbidities complicating radiotherapy.

VSCC-related recurrence and death rates are consistently predicted by nodal involvement as inguinal lymph node metastases continue to be the most important prognostic factor for both PFS and OS (3-year PFS and OS rates of $35.2 \%$ and $56.2 \%$, respectively, in node-positive patients versus $75.2 \%$ and $90.2 \%$, respectively, in node-negative patients). ${ }^{3,5,10,13,14}$ The number of affected groin nodes thereby correlates with survival (27\% 2-year OS for patients with four or more positive groin nodes, $66 \%$ 2-year OS for patients with two to three positive groin nodes, and $88 \%$ 2-year OS for patients with only one positive groin node; $p<0.0001){ }^{5,15}$ One possible reason for this relation might be the increasing risk for pelvic nodal involvement with the increasing number of groin nodes affected.
Furthermore, the risk for pelvic metastases seems to be only relevant in highly groin node-positive disease. However, the prediction of pelvic nodal involvement in view of inguinal metastases with a clinically sufficient specificity remains an unresolved issue.

Hacker et al. were one of the first to determine pelvic nodal involvement in patients with positive groin nodes. ${ }^{8}$ In their study, neither initial pelvic involvement nor pelvic recurrence were observed in cases of two or fewer positive groin nodes, while $2 / 3$ patients $(66.6 \%)$ with three positive groin nodes and $5 / 6$ patients $(83.3 \%)$ with four or more positive groin nodes experienced pelvic nodal involvement. Irrespective thereof, no patients with confirmed pelvic metastasis were cured of the disease. An increased risk for pelvic involvement in patients with three or more positive groin nodes was also observed in other small cohorts. ${ }^{8,16}$ In our cohort, a clinically valid prediction of pelvic involvement could only be made in cases of six or more positive groin nodes. Unfortunately, information regarding certain decisive factors with potential influence on the description of the relation between inguinal and pelvic nodes, such as laterality of the pelvic metastases, was not documented in the CaRE-1 database.

Of note, a relevant proportion of patients in the investigated cohort were receiving pelvic LAE despite histologically negative groin nodes $(>20 \%)$. The reasons for this can only be speculated on, but reactive enlargement of groin nodes clinically suspicious for metastatic disease might be the main factor. It has been described that in up to $30 \%$ of clinical examinations, groin nodes are categorized as suspicious, although histology later does not show metastases. ${ }^{8}$ Furthermore, the role of imaging in earlystage VSCC remains debatable. The accuracy of sonography ranges between 67 and $89 \%,{ }^{17}$ the sensitivity of magnetic resonance imaging is $89 \%$ with accuracy of

TABLE 3 Site of disease recurrence

\begin{tabular}{|c|c|c|c|c|}
\hline $\begin{array}{l}\text { Localization of } \\
\text { disease } \\
\text { recurrence }\end{array}$ & $\begin{array}{l}\text { Total }(n=70 \text { patients), } \\
30 \text { recurrences }[42.9 \%]\end{array}$ & $\begin{array}{l}\text { Node-negative pelvis }(n=43 \\
\text { patients), } 17 \text { recurrences } \\
{[39.5 \%]}\end{array}$ & $\begin{array}{l}\text { Node-positive pelvis }(n=14 \\
\text { patients), } 8 \text { recurrences } \\
(57.1 \%)\end{array}$ & $\begin{array}{l}\text { Pelvic status unknown } \\
(n=13), 5 \text { recurrences } \\
(38.5 \%)\end{array}$ \\
\hline No recurrence & $32(45.7)$ & $22(51.2)$ & 4 (28.6) & $6(46.2)$ \\
\hline Vulva only & 15 (21.4) & $10(23.3)$ & $3(21.4)$ & $2(15.4)$ \\
\hline Groin only & $1(1.4)$ & $1(2.3)$ & 0 & 0 \\
\hline Vulva + groin & $3(4.3)$ & 0 & $1(7.1)$ & $2(15.4)$ \\
\hline $\begin{array}{r}\text { Pelvis ( } \pm \text { other } \\
\text { localizations) }\end{array}$ & $4(5.7)$ & $3(7)$ & 0 & $1(7.7)$ \\
\hline $\begin{array}{c}\text { Distant ( } \pm \text { other } \\
\text { localizations) }\end{array}$ & $7(10)$ & $3(7)$ & 4 (28.6) & 0 \\
\hline $\begin{array}{l}\text { Death before } \\
\text { recurrence }\end{array}$ & $8(11.4)$ & $4(9.3)$ & $2(14.3)$ & $2(15.4)$ \\
\hline
\end{tabular}

Data are expressed as $n(\%)$ 
FIG. 2 Progression-free survival and overall survival with regard to pelvic lymph node status

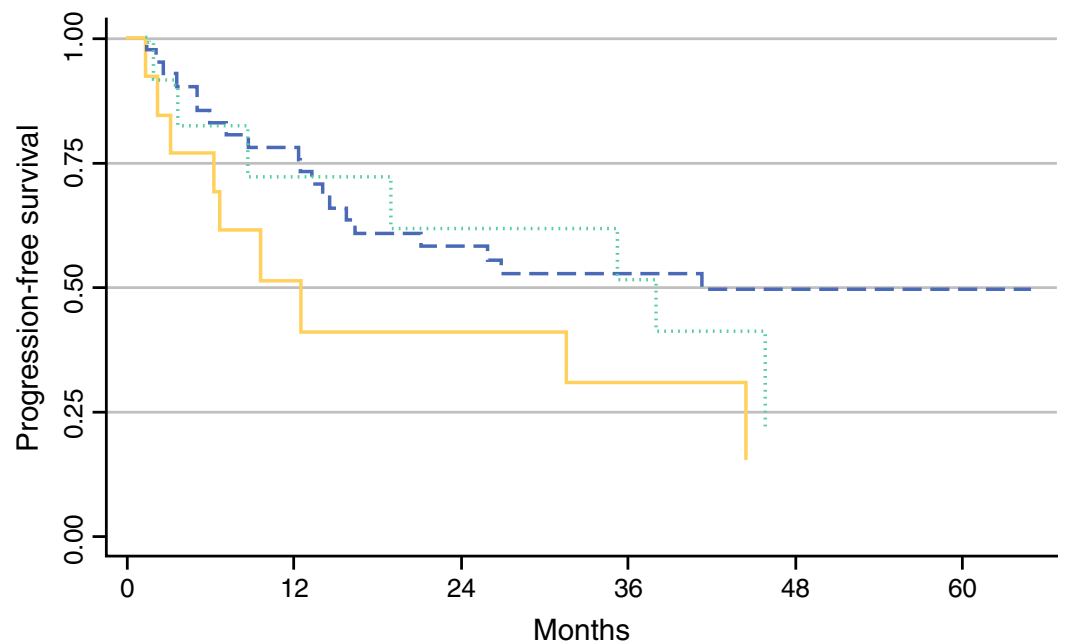

Number at risk

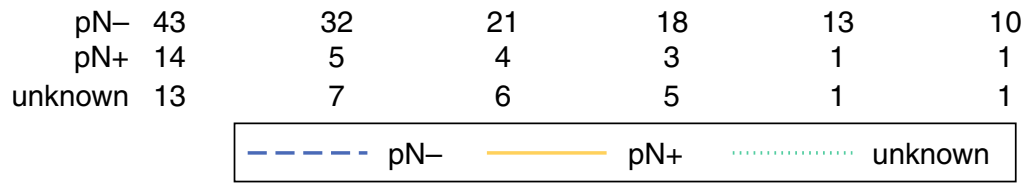

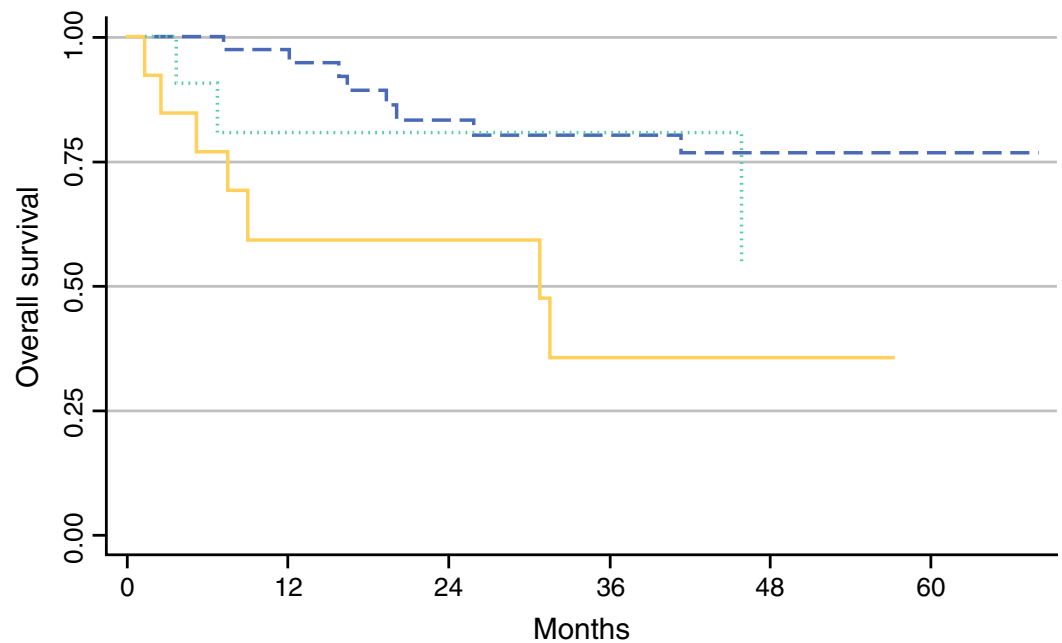

Number at risk

$\mathrm{pN}-43$

$\mathrm{pN}+14$

unknown 13

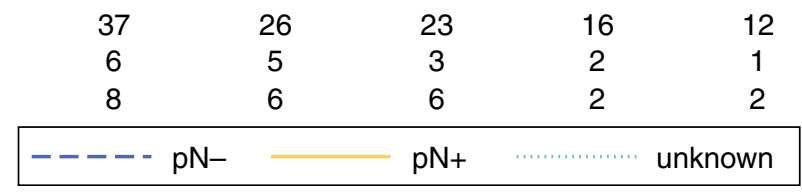

$90 \%{ }^{18}$ and the sensitivity of positron emission tomography (PET) is only $80 \%$ for the detection of lymph node metastases. ${ }^{19}$ Thus, imaging will not solve the problem of prediction of pelvic lymph node involvement in most cases. $^{20}$ Simultaneous pelvic LAE without previous confirmation of groin metastases should therefore be avoided.

In accordance with the previous data, pelvic nodal involvement without groin metastases was not observed in our study. Another notable finding from our analysis is that while $28.6 \%$ of pelvic node-positive patients experienced recurrences at distant sites (4/14), no pelvic recurrences were observed in the pelvic node-positive subgroup (in contrast to the pelvic node-negative group, in which a $7 \%$ pelvic recurrence rate was observed). One could now speculate that this is an effect of adjuvant pelvic radiotherapy in the node-positive group or a lack of surgical radicality during $\mathrm{LAE}$ in the node-negative group. Furthermore, the omittance of pelvic radiotherapy in the case of negative pelvic staging could possibly increase the risk of pelvic recurrence in the node-negative group. In this 
context, Curry et al. also reported a pelvic rate of recurrence in at least $8 \%$ in patients who had fewer than four positive inguinal lymph nodes and whose pelvic lymph nodes were initially node-negative. ${ }^{9}$ However, Homesley et al. reported a slightly lower rate of pelvic recurrence of $4.4 \%$ (5/114 patients) in their total patient population and $1.8 \%$ (1/55 patients) in the cohort treated with pelvic LAE. ${ }^{5}$ Taken together, pelvic LAE might have been of beneficial impact, or rather the omittance of pelvic radiotherapy in the pelvic node-negative group might have increased the risk for pelvic recurrences. Data regarding the effectiveness of chemotherapy in pelvic node-positive patients and patients with distant/pelvic recurrences are even more sparse. The most commonly used agents are paclitaxel, bleomycin, cisplatin, and 5-fluorouracil; however, numbers are too small to draw a conclusion.

Although the CaRE-1 study represents one of the largest VSCC cohorts, our results show that only a small number of patients receive pelvic LAE (70/1618, 4.3\%), including a considerably high rate of inguinal node-negative patients $(16 / 70,22.9 \%)$. A future goal is to precisely predict who is at risk for pelvic involvement while simultaneously preventing overtreatment and unnecessary harm to a majority of mostly older and comorbid patients.

The current study shows that only patients with a high disease burden in the groin seem to be at danger, but the numbers are to small to put this into clinical practice. Therefore, our team along with the German AGO study group have already received permission from the Ethics Committee to commence a multicenter trial of 35 centers in Germany (AGO-VOP.2) in order to evaluate the relation of inguinal and pelvic nodal metastases and the optimal treatment approach.

\section{CONCLUSION}

In view of the poor prognosis, the relatively low incidence of pelvic nodal involvement, and the associated increase in surgery-related morbidity, surgical staging of the pelvis appears unnecessary for the majority of patients with inguinal node-positive VSCC. However, in a subset of patients at high risk for pelvic nodal involvement, pelvic LAE might represent an alternative approach for omitting radiotherapy of the pelvis in cases of negative pelvic lymph node status, e.g. in younger patients with open family planning. Further systematic data, as planned by the German AGO study group, the AGO Kommission Vulva Vagina, and the Nord-Ostdeutsche Gesellschaft für Gynäkologische Onkologie (NOGGO) is needed to further investigate the indication criteria for pelvic $\mathrm{LAE}$, as well as the impact of the latter on the prognosis and outcome of affected patients.
AUTHOR CONTRIBUTIONS All authors have made substantial intellectual contributions to the article, provided critical feedback, and given approval of the final manuscript to be published. LW and SM initially designed and coordinated the multicenter AGO-CaRE-1 study and multiple subprojects. In the present subanalysis, LW, MB, and $\mathrm{AJ}$ took the lead in writing the manuscript and were responsible for the conception/design of the article and data collection and interpretation. CE statistically analyzed and interpreted the patient data, and KP statistically analyzed and interpreted the data and helped draft the manuscript. JJ, FH, NG, SI, JS, AI, PH, SF, H-GS, KB, MB, $\mathrm{AM}$, and WM supervised the project by providing substantial feedback and revising it critically for intellectual content.

FUNDING Open Access funding enabled and organized by Projekt DEAL..

DISCLOSURES The AGO-CaRE- 1 study was supported by Medac Oncology without restriction in protocol or analysis.

OPEN ACCESS This article is licensed under a Creative Commons Attribution 4.0 International License, which permits use, sharing, adaptation, distribution and reproduction in any medium or format, as long as you give appropriate credit to the original author(s) and the source, provide a link to the Creative Commons licence, and indicate if changes were made. The images or other third party material in this article are included in the article's Creative Commons licence, unless indicated otherwise in a credit line to the material. If material is not included in the article's Creative Commons licence and your intended use is not permitted by statutory regulation or exceeds the permitted use, you will need to obtain permission directly from the copyright holder. To view a copy of this licence, visit http://creativecommons. org/licenses/by/4.0/.

\section{REFERENCES}

1. Boyce J, Fruchter RG, Kasambilides E, Nicastri AD, Sedlis A, Remy JC. Prognostic factors in carcinoma of the vulva. Gynecol Oncol. 1985;20(3):364-77. https://doi.org/10.1016/0090-8258(8 5)90218-5.

2. Hacker NF, van der Velden J. Conservative management of early vulvar cancer. Cancer. 1993;71(4 Suppl):1673-7.

3. Klemm P, Marnitz S, Köhler C, Braig U, Schneider A. Clinical implication of laparoscopic pelvic lymphadenectomy in patients with vulvar cancer and positive groin nodes. Gynecol Oncol. Oct ;99(1):101-5. https://doi.org/10.1016/j.ygyno.2005.05.027.

4. van der Velden J, van Lindert AC, Lammes FB. Extracapsular growth of lymph node metastases in squamous cell carcinoma of the vulva. The impact on recurrence and survival. Cancer. 1995;75(12):2885-90.

5. Homesley HD, Bundy BN, Sedlis A, Adcock L. Radiation therapy versus pelvic node resection for carcinoma of the vulva with positive groin nodes. Obstet Gynecol. Dec ;68(6):733-40.

6. Hacker NF, Eifel PJ, van der Velden J. Cancer of the vulva. Int J Gynaecol Obstet. Oct ;131(Suppl 2):S76-83. https://doi.org/10. 1016/j.ijgo.2015.06.002.

7. National German Guideline S2k. Diagnosis, Therapy, and Follow-Up Care of Vulvar Cancer and its Precursors, AWMF Registry No. 015/059. http://www.awmf.org/leitlinien/Diagnose ,TherapieundNachsorgedesVulvakarzinomsundseinerVorstufen/i i/015-059.html

8. Hacker NF, Berek JS, Lagasse LD, Leuchter RS, Moore JG. Management of regional lymph nodes and their prognostic influence in vulvar cancer. Obstet Gynecol. Apr ;61(4):408-12. 
9. Curry SL, Wharton JT, Rutledge F. Positive lymph nodes in vulvar squamous carcinoma. Gynecol Oncol. Feb ;9(1):63-7. h ttps://doi.org/10.1016/0090-8258(80)90009-8.

10. Mahner S, Jueckstock J, Hilpert F, et al. Adjuvant therapy in lymph node-positive vulvar cancer: the AGO-CaRE-1 study. $J$ Natl Cancer Inst. 2015;107(3):dju426. https://doi.org/10.1093/jnc $\mathrm{i} / \mathrm{dju} 426$.

11. American Joint Commission on Cancer. AJCC Cancer Staging Manual. 6th ed. 2002. https://cancerstaging.org/references-tools/ deskreferences/Pages/default.aspx. Accessed 10 Nov 2014.

12. Union for International Cancer Control. TNM classification of malignant tumours. New York: Wiley; 2002.

13. Mitra S, Sharma MK, Kaur I, et al. Vulvar carcinoma: dilemma, debates, and decisions. Cancer Manag Res. 2018;10:61-8. http s://doi.org/10.2147/CMAR.S143316.

14. Papadia A, Ehm L, Gasparri ML, Wang J, Radan AP, Mueller MD. Unilateral versus bilateral lymph-nodal metastases and oncologic outcome in vulvar cancer patients. J Cancer Res Clin Oncol. 2020;146(7):1877-81. https://doi.org/10.1007/s00432-02 0-03196-9.

15. Woelber L, Eulenburg C, Choschzick M, et al. Prognostic role of lymph node metastases in vulvar cancer and implications for adjuvant treatment. Int J Gynecol Cancer. 2012;22(3):503-8. h ttps://doi.org/10.1097/IGC.0b013e31823eed4c.

16. Oonk MH, van Hemel BM, Hollema H, et al. Size of sentinelnode metastasis and chances of non-sentinel-node involvement and survival in early stage vulvar cancer: results from GROINSS$\mathrm{V}$, a multicentre observational study. Lancet Oncol. 2010;11(7):646-52. https://doi.org/10.1016/S1470-2045(10)7010 4-2.

17. Abang Mohammed DK, Uberoi R, Lopes ADB, Monaghan JM. Inguinal node status by ultrasound in vulva cancer. Gynecol Oncol. 2000;77(1):93-6. https://doi.org/10.1006/gyno.1999.5702.

18. Hawnaur JM, Reynolds K, Wilson G, Hillier V, Kitchener HC. Identification of inguinal lymph node metastases from vulval carcinoma by magnetic resonance imaging: an initial report. Clin Radiol. 2002;57(11):995-1000. https://doi.org/10.1053/crad.200 2.1057.

19. Cohn DE, Dehdashti F, Gibb RK, et al. Prospective evaluation of positron emission tomography for the detection of groin node metastases from vulvar cancer. Gynecol Oncol. 2002;85(1):179-84. https://doi.org/10.1006/gyno.2002.6605.

20. de Gregorio N, Ebner F, Schwentner L, et al. The role of preoperative ultrasound evaluation of inguinal lymph nodes in patients with vulvar malignancy. Gynecol Oncol. 2013;131(1):113-7. https://doi.org/10.1016/j.ygyno.2013.07.103.

Publisher's Note Springer Nature remains neutral with regard to jurisdictional claims in published maps and institutional affiliations. 